\title{
Efeito da adição de própolis e monensina sódica na digestibilidade e características ruminais em bubalinos alimentados com dieta à base de forragem ${ }^{1}$
}

\section{Odimári Pricila Pires do Prado2,3, Lucia Maria Zeoula 3,4, Lucimar Pontara Peres de Moura4, Selma Lucy Franco ${ }^{5}$, Ivanor Nunes do Prado ${ }^{3,4}$, Guido Jacobi ${ }^{6}$}

\author{
1 Pesquisa financiada pelo CNPq e pela Fundação Araucária. \\ 2 Doutoranda em Zootecnia - UEM. \\ ${ }^{3}$ Bolsista do CNPq. \\ ${ }^{4}$ Departamento de Zootecnia - UEM. \\ 5 Departamento de Farmácia - UEM. \\ ${ }^{6}$ Granduando em Zootecnia - Bolsista IC/CNPq - UEM.
}

RESUMO - Objetivou-se avaliar o efeito da administração de produtos à base de monensina sódica ou de própolis LLOSB3 e LLOSC1 em duas concentrações (B e C, em que B foi menos concentrado que C) e duas extrações alcoólicas (1 e 3, em que 1 foi menos concentrado que 3) sobre o consumo, a digestibilidade total e parcial e as características ruminais em bubalinos alimentados com dieta à base de forragem. Foram utilizados quatro búfalos castrados mestiços com 459,3 \pm 44,5 kg em delineamento quadrado latino $4 \times 4$, com quatro dietas (controle, monensina, LLOSC1 e LLOSB3) e quatro períodos. A dieta continha $80 \%$ de volumoso (silagem de milho e feno de capim-tifton) e $20 \%$ de concentrado, com $11,1 \%$ de $\mathrm{PB}$ e $66 \%$ de nutrientes digestíveis totais (NDT). Os consumos de matéria seca (MS) e nutrientes não diferiram entre os aditivos testados. A adição de LLOSC1 propiciou maiores coeficientes de digestibilidade total em relação ao controle para MS (62,8\% vs 59,4\%), FDN (58,6\% vs 54,3\%), carboidratos totais (65,1\% vs 61,5\%) e NDT (65,8 vs 62,3\%). A dieta com monensina não diferiu da controle e aquela com LLOSB3 foi semelhante a todas as outras. Aumento no fluxo e maior digestibilidade de PB nos intestinos foram verificados com o uso dos aditivos em relação à dieta controle. Após a alimentação, às 2,18 horas, não houve diferença na concentração de nitrogênio amoniacal no rúmen entre dietas e o valor máximo foi de 21,26 mg/100 mL. Menor valor de pH ruminal $(6,48)$ e maiores concentrações de acetato e de butirato foram verificados para LLOSB3. A taxa de passagem de líquido não diferiu entre as dietas, porém, maior volume ruminal foi verificado com o uso dos aditivos. O aditivo LLOSC1 é superior à monensina em aumentar a energia digestível para bubalinos alimentados com dietas à base de forragem.

Palavras-chave: ácidos graxos voláteis, aditivos, consumo, digestibilidade parcial, nitrogênio amoniacal

\section{Effect of propolis and sodium monensin addition on digestibility and ruminal characteristics of buffaloes fed diet based on roughage}

ABSTRACT - The objective of this work was to study the effect of the administration of products based on sodium monesin or propolis LLOSB3 and LLOSC1 in two concentrations (B and C, in which B was less concentrated than C) and two alcoholic extractions (1 and 3, in which 1 was less concentrated than 3) on intake, total and partial digestibility, and ruminal characteristics in buffaloes fed diet based on roughage. It was used four castrated crossbred buffalo with average weight of $459.3 \pm 44.5 \mathrm{~kg}$ in $4 \times 4$ experimental Latin square design with four diets (control, monensin, LLOSC1 and LLOSB3) and four periods. The diet had $80 \%$ roughage (corn silage and Tifton hay) and $20 \%$ concentrate, with $11.1 \%$ CP and $66 \%$ of total digestible nutrients (TDN). The intake of dry matter (DM) and nutrients did not differ among tested additives. The addition of LLOSC1 provided higher total digestibility coefficients in relation to the control for dry matter (62.8\% vs. 59.4\%), NDF (58.6\% vs. $54.3 \%)$, total carbohydrates (65.1\% vs. $61.5 \%$ ) and TDN (65.8 vs. $62.3 \%)$. The diet with monensin did not differ from the control and the diet with LLOSB3 was similar to all other diets. Increase in the flow and higher digestibility of CP in the intestines were found with the use of additives in relation to the control diet. After feeding at $2.18 \mathrm{~h}$, there was no difference in the concentration of ammoniacal nitrogen in the rumen among diets and the maximum value was $21.26 \mathrm{mg} / 100 \mathrm{~mL}$. The lowest value of ruminal $\mathrm{pH}$ (6.48) and higher concentrations of acetate and butyrate were found for LLOSB3. The passage rate of liquid did not differ among diets, however greater ruminal volume was found with the use of additives. The additive LLOSC1 is superior than monensin in increasing digestible energy for buffalo fed diets based on roughage.

Key Words: additives, ammonia nitrogen, intake, partial digestibility, volatile fatty acids 


\section{Introdução}

A criação de búfalos tem crescido em termos produtivos e em mercado consumidor, principalmente por aquele que conhece a qualidade de seus produtos. O Brasil destaca-se como o maior criador de búfalos do ocidente com três milhões e meio de cabeças e com crescimento anual de 3,0\%, segundo ABCB (Bernardes, 2007).

O leite e a carne dos bubalinos possuem qualidades peculiares que podem superar as dos bovinos, como a produção de mozzarella do leite de búfala com maior percentual de proteínas, gorduras, cálcio, fósforo e sabor adocicado (Amaral et al., 2005), e a carne apresenta maciez e suculência, além de baixos teores de gordura e de composição de ácidos graxos de menor aterogenicidade e trombogenicidade (Lira et al., 2005).

Em sua maioria, a criação de búfalos é feita de forma extensiva para produção de carne, e semiextensiva para produção de leite, tendo a forragem como principal alimento. O menor aproveitamento energético, proporcionado pelo padrão de fermentação ruminal da forragem, acarreta em produção de metano, gás prejudicial ao planeta e que contribui para o aquecimento global (Johnson \& Johnson, 1995). Todavia, modificadores da fermentação ruminal, como os ionóforos, podem reduzir a produção de metano e, consequentemente, aumentar a eficiência energética e o desempenho animal, além de reduzir a degradação da proteína dietética (Spears, 1990).

O efeito da monensina sódica sobre a fermentação in vitro, utilizando-se líquido ruminal de bovinos alimentados com rações ricas em volumoso ou concentrado, foi verificado por Lana et al. (2001), os quais concluíram que, recebendo forragem, as bactérias ruminais provenientes do conteúdo ruminal de animais apresentaram maior sensibilidade ao ionóforo. Entretanto, lacunas ainda permaneceram sobre o efeito de ionóforos em dietas à base de forragem, principalmente quanto ao seu uso para bubalinos.

A própolis, mais recentemente, tem sido estudada como modificador da fermentação ruminal devido a sua ação antimicrobiana e mostrado resultados positivos como aditivo alimentar natural em ruminantes (Stradiotti et al., 2004). Semelhante aos ionóforos, a própolis reduziu a produção de amônia a partir de fontes proteicas (Oliveira et al., 2004) e melhorou a digestibilidade in vitro de dietas à base de forragem (Prado, 2005).

Há relatos de que a própolis não influencia o consumo, a digestibilidade e o desempenho de vacas produzindo $20 \mathrm{~kg}$ de leite/dia (Stelzer et al., 2009), nem as características de carcaça de ovinos terminados em confinamento (Ítavo et al., 2009).

Neste trabalho, objetivou-se avaliar os efeitos de produtos à base de própolis em duas concentrações e duas extrações alcoólicas e da monensina sódica na dieta à base de forragem sobre o consumo, a digestibilidade e as características ruminais de bubalinos.

\section{Material e Métodos}

O experimento foi realizado no setor de Bovinocultura de Corte da Fazenda Experimental de Iguatemi, no Laboratório de Alimentação e Nutrição Animal e no Laboratório de Farmacotécnica da Universidade Estadual de Maringá (UEM).

Foram utilizados quatro búfalos mestiços castrados com peso corporal inicial de 459,3 $\pm 44,5 \mathrm{~kg}$. Os animais foram fistulados no rúmen e mantidos em baias individuais cobertas, com piso de concreto, providas de comedouro e bebedouro.

Os animais foram alimentados com uma dieta com razão volumoso:concentrado de 80:20\% e balanceadas para conter $66 \%$ de nutrientes digestíveis totais e $11 \%$ de proteína bruta (Tabela 1). As dietas experimentais diferiram somente para

Tabela 1 - Composição nutricional dos ingredientes da ração experimental

\begin{tabular}{|c|c|c|c|c|c|c|c|c|}
\hline & \multicolumn{7}{|c|}{ Alimento } & \multirow{2}{*}{$\begin{array}{c}\text { Dieta total } \\
(80: 20)^{2}\end{array}$} \\
\hline & $\begin{array}{l}\text { Silagem } \\
\text { de milho }\end{array}$ & $\begin{array}{c}\text { Feno } \\
\text { de tifton }\end{array}$ & $\begin{array}{l}\text { Farelo } \\
\text { de soja }\end{array}$ & $\begin{array}{l}\text { Milho } \\
\text { moído }\end{array}$ & Ureia & $\begin{array}{c}\text { Óleo } \\
\text { de soja }\end{array}$ & $\begin{array}{c}\text { Sal } \\
\text { mineral }^{1}\end{array}$ & \\
\hline Matéria seca (\%) & 34,5 & 94,0 & 91,7 & 90,6 & 99,0 & 99,0 & 99,0 & 57,9 \\
\hline Matéria orgânica (\% MS) & 95,2 & 95,4 & 93,6 & 98,8 & - & - & - & 92,9 \\
\hline Proteína bruta (\% MS) & 7,5 & 5,2 & 50,4 & 8,8 & 312,1 & - & - & 11,1 \\
\hline Extrato etéreo (\% MS) & 2,4 & 0,8 & 2,1 & 3,1 & - & 99,9 & - & 3,2 \\
\hline Fibra em detergente neutro (\% MS) & 60,2 & 82,8 & 10,7 & 15,4 & - & - & - & 55,1 \\
\hline Fibra em detergente ácido (\% MS) & 36,7 & 42,2 & 10,3 & 4,0 & - & - & - & 31,4 \\
\hline Carboidratos totais (\% MS) & 85,3 & 89,5 & 41,1 & 86,9 & - & - & - & 82,0 \\
\hline Carboidratos não-estruturais (\% MS) & 25,1 & 6,7 & 30,5 & 71,4 & - & - & - & 26,9 \\
\hline$\%$ na dieta & 60,0 & 20,0 & 4,45 & 12,73 & 0,72 & 1,1 & 1,0 & 100 \\
\hline
\end{tabular}

${ }^{1}$ Composição por quilo de sal mineral: P - 65,0 g; Ca - 130,0 g; Mg - 5,0 g; S - 13,0 g; Fe - 700 mg; Cu - 850 mg; Mn - 1.000 mg; I - 120 mg; Co - 80 mg.

2 Relação volumoso:concentrado. 
a inclusão ou não dos aditivos sendo denominados: controle (sem aditivo), monensina sódica, LLOSC1 e LLOSB3.

Os produtos contendo própolis (LLOSC1 e LLOSB3), em pó, patenteados como patrimônio intelectual sob o $n^{\circ} \mathrm{PI}$ 0605768-3, foram preparados de acordo com a metodologia desenvolvida por Franco \& Bueno (1999), em duas concentrações de própolis (B e C) e duas extrações alcoólicas (1 e 3). As concentrações de flavonoides totais, medidas em concentrações de crisina, por análise cromatográfica (Cromatografia Líquida de Alta Eficiência), foi de 0,018 mg/g de LLOSC1 e de 0,011 mg/g de LLOSB3 (Prado, 2005). Produtos à base de própolis (LLOS) com diferentes concentrações de própolis (A, B, C e D) e teores alcoólicos (1, 2 e 3) foram anteriormente avaliados em estudos in vitro, sendo os produtos LLOSC1 e LLOSB3 selecionados porque propiciaram maior valor de DIVMS do feno de tifton em relação ao controle e monensina sódica (Prado, 2005).

Para o fornecimento de monensina sódica, foi utilizado o produto comercial Rumensin ${ }^{\circledR}$ que contém $10 \%$ do princípio ativo, e a dose fornecida, de acordo com o fabricante, foi de $2 \mathrm{~g}$ do produto/animal/dia. As doses dos produtos contendo própolis (LLOS) foram calculadas de maneira que as concentrações de própolis avaliadas estivessem contidas também em $2 \mathrm{~g}$ de produto LLOS/ animal/dia.

Todos os aditivos foram pesados em separado e embalados em papel higroscópico que continha $1 \mathrm{~g}$ do aditivo. Os aditivos foram colocados diretamente no rúmen do animal por meio da cânula ruminal, no momento da alimentação matutina (8h) e da vespertina (16h), assegurando, desta forma, o fornecimento da dose diária de $2 \mathrm{~g}$ de aditivo.

Cada período experimental foi de 20 dias (ao todo, quatro períodos), sendo 14 dias para adaptação dos animais aos aditivos e seis dias para coleta. Do primeiro ao quarto dia do período de coleta, foram amostrados cerca de $400 \mathrm{~mL}$ de digesta omasal/dia, obtida por sucção do conteúdo omasal, por meio do orifício retículo-omasal, segundo técnica descrita por Leão et al. (2005). No primeiro dia, a coleta foi realizada às $8 \mathrm{~h}$; no segundo dia, às $12 \mathrm{~h}$; no terceiro, às $16 \mathrm{~h}$, e no quarto dia às $20 \mathrm{~h}$ (perfazendo um total de quatro amostras por animal em cada período). Os dois últimos dias de coleta foram utilizados para a coleta de líquido ruminal e conteúdo ruminal para avaliar as características da fermentação. Os animais foram pesados no final de cada período de adaptação e de coleta para estimar o consumo de matéria seca e de nutrientes em relação ao peso corporal (PC) dos animais.

Para determinação do $\mathrm{pH}$, nitrogênio amoniacal $\left(\mathrm{N}-\mathrm{NH}_{3}\right)$ e ácidos graxos voláteis (AGV), o fluido ruminal foi coletado no quinto dia do período de coleta, via cânula ruminal, nos tempos zero, 2, 4, 6 e 8 horas após a alimentação da manhã. $\mathrm{O}$ pH foi determinado imediatamente após a coleta. Aproximadamente $50 \mathrm{~mL}$ foram acidificados com 1 mL de ácido sulfúrico 1:1 para posteriores determinações das concentrações de $\mathrm{N}-\mathrm{NH}_{3}$ e AGV.

Foi administrado, via cânula, diretamente no rúmen dos animais, 30 g de Co-EDTA diluído em $500 \mathrm{~mL}$ de água destilada antes da primeira alimentação e infundido em dose única para a determinação da taxa de passagem de líquidos (Uden et al., 1980). Foram coletados cerca de $50 \mathrm{~mL}$ de líquido ruminal antes da infusão, a cada duas horas, até completar 12 h, e uma última coleta às 24 h, após a administração do marcador.

Durante o período experimental, foram feitas pesagens diárias do alimento fornecido e das sobras, que foram amostrados e armazenados. Todas as amostras, como também as de líquido e conteúdo ruminal, foram armazenadas separadas em embalagens plásticas específicas, as quais foram previamente etiquetadas e congeladas a $-20^{\circ} \mathrm{C}$ para posteriores análises químicas.

Para determinação dos fluxos diários de matéria seca no rúmen, no intestino e nas fezes foi utilizado o óxido crômico $\left(\mathrm{Cr}_{2} \mathrm{O}_{3}\right)$ como indicador externo. Foram fornecidas duas doses intrarruminais diariamente (às 8 h e 16 h) de cinco gramas de óxido crômico, previamente, pesado e acondicionado em papel higroscópico, perfazendo um total de $10 \mathrm{~g}$ de $\mathrm{Cr}_{2} \mathrm{O}_{3}$ /dia. As concentrações de óxido de cromo nas amostras de digesta omasal e fezes foram determinadas por meio de espectrofotômetro de absorção atômica, após digestão nitro-perclórica (Kimura \& Miller, 1957).

A dosagem de amônia nas amostras de líquido ruminal foi realizada pela técnica de Fenner (1965). O líquido de rúmen foi analisado para ácidos graxos voláteis pela metodologia descrita por Bock et al. (1991).

Os teores de matéria seca, matéria orgânica, proteína bruta e extrato etéreo foram determinados segundo AOAC (1980), citados em Silva \& Queiroz (2002). As determinações de fibra em detergente neutro e da fibra em detergente ácido foram conduzidas de acordo com Van Soest et al. (1991).

Para a quantificação dos carboidratos totais (CHT) e não-estruturais (CNE), utilizaram-se as equações descritas por Sniffen et al. (1992): CHT = 100 - (\%PB + \%EE + \%Cinzas) e $\mathrm{CNE} \%=100-(\% \mathrm{~PB}+\% \mathrm{FDN}+\% \mathrm{EE}+\%$ Cinzas $)$. Os valores de NDT observados foram calculados para as diferentes dietas pela equação: NDT $=$ PBD + EED*2,25 + CHTD, em que PBD = proteína bruta digestível; EED = extrato etéreo digestível; CHTD = carboidratos totais digestíveis. 
Os coeficientes de digestibilidade totais e parciais da matéria seca e demais nutrientes foram calculados de acordo com as fórmulas descritas por Coelho da Silva \& Leão (1979).

A taxa de passagem de líquido e as curvas de concentração ruminal do cobalto foram ajustadas ao modelo exponencial unicompartimental de Hungate (1966), citado por Colucci (1984): $\mathrm{YCo}=\mathrm{A} \mathrm{x} \mathrm{e}^{(-\mathrm{kl} . \mathrm{t})}$, em que $\mathrm{Y}_{\mathrm{Co}}=$ concentração do indicador no tempo t; $\mathrm{A}$ = concentração de equilíbrio do Co; kl = taxa de passagem ou de diluição do Co; $\mathrm{t}$ = tempo de amostragem. Os parâmetros da dinâmica da fase líquida foram calculados de acordo com Colucci et al. (1990): Tempo de retenção no rúmen $(h)=1$ / taxa de passagem de fluidos $(\% / h)$; Volume de líquido ruminal $(\mathrm{L})=$ quantidade de Co fornecida (mg)/A; Taxa de fluxo ruminal $(\mathrm{L} / \mathrm{h})=\mathrm{k}_{\mathrm{lCo}} \mathrm{x}$ VLR; Taxa de reciclagem da fase líquida ruminal $\left(\mathrm{n}^{\circ}\right.$ de vezes/dia) $=24 \mathrm{~h} / \mathrm{TeR}$ (calculada conforme Maeng \& Baldwin, 1976).

Os dados foram analisados em delineamento experimental com quadrado latino $4 \times 4$ (quatro animais, quatro períodos e quatro dietas). As análises estatísticas das variáveis estudadas, incluindo os dados da dinâmica da fase líquida, foram interpretadas no Sistema de Análises Estatísticas (SAS, 1987) por meio de análise de variância no procedimento PROC GLM.

Para os valores de $\mathrm{pH}, \mathrm{N}-\mathrm{NH}_{3}$ e ácidos graxos voláteis procederam-se à subdivisão de parcelas experimentais em função dos tempos de amostragem. Foi utilizada a análise de regressão para as concentrações de $\mathrm{pH}, \mathrm{N}-\mathrm{NH}_{3}$ e ácidos graxos voláteis do líquido ruminal em função do tempo após a alimentação da manhã $(0,2,4,6,8$ h) para cada dieta, e o efeito de hora foi desdobrado em polinômio ortogonal. As diferenças entre as médias das dietas foram determinadas pelo teste Tukey, considerando 5\% o grau de significância e até $10 \%$ de probabilidade como tendência.

\section{Resultados e Discussão}

Não houve diferença $(\mathrm{P}>0,05)$ para o consumo de matéria seca e de componentes nutritivos entre as dietas com valores médios de matéria seca, proteína bruta, fibra em detergente neutro e nutrientes digestíveis totais, respectivamente, de: 1,$91 ; 0,21 ; 1,05$ e $1,21 \%$ do peso corporal (PC) (Tabela 2). Os consumos de matéria seca e proteína bruta observados estão de acordo com os reportados por Beleze (2005), para búfalos alimentados com rações contendo $11 \%$ de proteína bruta e relação volumoso:concentrado de 80:20\%, porém, o consumo de fibra em detergente neutro observado foi inferior ao observado pelo referido autor (1,32\% PC), que utilizou feno de capim-tifton 85 como único volumoso.

A influência da monensina no consumo foi avaliada em bovinos por Oliveira et al. (2005), que observaram redução expressiva na ingestão de matéria seca de $2,65 \mathrm{~kg} / \mathrm{animal} / \mathrm{dia}$ em dietas com baixo teor de proteína e redução de 1,22 kg/ animal/dia para alto teor de proteína. O efeito de monensina sódica e levedura em dieta à base de forragem em bovinos e bubalinos também foi estudado por Beleze (2005), que observou, independente da espécie, diminuição no consumo de matéria seca de $0,15 \mathrm{~kg} /$ dia para monensina sódica em relação ao controle, inferior à redução de $0,30 \mathrm{~kg} / \mathrm{dia}$ observada no presente estudo (Tabela 2).

Tabela 2 - Consumos médios de bubalinos alimentados com dieta à base de forragem sem ou com adição de monensina e própolis LLOS ${ }^{1}$

\begin{tabular}{|c|c|c|c|c|c|c|c|}
\hline & & \multicolumn{4}{|c|}{ Dieta } & \multirow[b]{2}{*}{$\mathrm{P}$} & \multirow[b]{2}{*}{$\mathrm{CV}$} \\
\hline & & Controle & Monensina & LLOSC1 & LLOSB3 & & \\
\hline \multirow[t]{2}{*}{ Matéria seca } & kg/dia & 10,0 & 9,7 & 9,7 & 10,0 & 0,663 & 4,17 \\
\hline & $\% \mathrm{PC}$ & 1,9 & 1,9 & 1,9 & 1,9 & 0,736 & 4,30 \\
\hline \multirow[t]{2}{*}{ Matéria orgânica } & kg/dia & 9,3 & 9,0 & 9,0 & 9,3 & 0,666 & 4,26 \\
\hline & $\% \mathrm{PC}$ & 1,8 & 1,8 & 1,8 & 1,8 & 0,738 & 4,40 \\
\hline \multirow[t]{2}{*}{ Proteína bruta } & kg/dia & 1,1 & 1,1 & 1,1 & 1,1 & 0,772 & 3,52 \\
\hline & $\%$ PC & 0,2 & 0,2 & 0,2 & 0,2 & 0,617 & 2,71 \\
\hline \multirow[t]{2}{*}{ Extrato etéreo } & kg/dia & 0,3 & 0,3 & 0,3 & 0,3 & 0,815 & 5,70 \\
\hline & $\%$ PC & 0,1 & 0,1 & 0,1 & 0,1 & 0,528 & 4,07 \\
\hline \multirow[t]{2}{*}{ Fibra em detergente neutro } & kg/dia & 5,6 & 5,4 & 5,4 & 5,5 & 0,676 & 5,01 \\
\hline & $\% \mathrm{PC}$ & 1,1 & 1,1 & 1,0 & 1,1 & 0,737 & 5,46 \\
\hline \multirow[t]{2}{*}{ Fibra em detergente ácido } & $\mathrm{kg} / \mathrm{dia}$ & 2,2 & 2,1 & 2,1 & 2,0 & 0,662 & 7,19 \\
\hline & $\% \mathrm{PC}$ & 0,4 & 0,4 & 0,4 & 0,4 & 0,569 & 7,91 \\
\hline \multirow[t]{2}{*}{ Carboidratos totais } & kg/dia & 8,2 & 8,0 & 7,9 & 8,2 & 0,642 & 4,38 \\
\hline & $\%$ PC & 1,6 & 1,55 & 1,54 & 1,58 & 0,747 & 4,66 \\
\hline \multirow[t]{2}{*}{ Carboidratos não estruturais } & kg/dia & 2,66 & 2,6 & 2,6 & 2,7 & 0,510 & 3,41 \\
\hline & $\%$ PC & 0,5 & 0,5 & 0,5 & 0,5 & 0,701 & 3,41 \\
\hline \multirow[t]{2}{*}{ Nutrientes digestíveis totais } & $\mathrm{kg} / \mathrm{dia}$ & 6,23 & 6,09 & 6,39 & 6,37 & 0,474 & 4,54 \\
\hline & $\%$ PC & 1,21 & 1,18 & 1,24 & 1,22 & 0,615 & 4,65 \\
\hline
\end{tabular}

Médias na mesma linha não diferem estatisticamente pelo teste Tukey a 5\%.

${ }^{1}$ LLOS: produto em pó à base de extrato de própolis em duas diferentes concentrações de própolis (B e C) e dois teores alcoólicos (1 e 3): LLOSC1 e LLOSB3. 
Houve diferença $(\mathrm{P}<0,05)$ para a digestibilidade total da matéria seca e dos nutrientes (Tabela 3 ). O produto à base de própolis, LLOSC1, destacou-se por apresentar os maiores coeficientes de digestibilidade total $(\mathrm{P}<0,05)$ para todos os componentes nutritivos estudados, exceto para proteína bruta e carboidratos não estruturais, que não diferiram. $\mathrm{O}$ produto LLOSC1 apresentou teor de nutrientes digestíveis totais próximos ao pré-estabelecido de $66 \%$ e foi superior $(\mathrm{P}<0,05)$ ao do controle e da monensina, que apresentaram teores de nutrientes digestíveis totais inferiores, média de $62 \%$. O produto LLOSB3 ficou com valor intermediário.

O aditivo contendo própolis, LLOSC1, propiciou maiores $(\mathrm{P}<0,05)$ coeficientes de digestibilidade totais da matéria seca e da matéria orgânica, que foram superiores a adição de monensina e controle e não diferiram entre si. A adição de produto LLOSB3 não diferiu das dietas testadas. Os resultados observados para adição de $\operatorname{LLOSC1}(\mathrm{P}<0,05)$ foram semelhantes àqueles obtidos por Prado (2005), quando avaliou LLOSC1 adicionado em dieta à base de feno sobre a digestibilidade in vitro da matéria seca (DIVMS) e observou maior valor em relação à adição de monensina e controle.

A digestibilidade total da matéria seca não diferiu entre o controle e a monensina sódica para búfalos, distinguindo-se daqueles divulgados por Lana et al. (2001), que testaram a susceptibilidade de células bacterianas e a monensina provenientes de dieta à base de forragem, observando maior sensibilidade da monensina que aquelas de animais recebendo dietas ricas em concentrado. Entretanto, os resultados encontrados foram semelhantes aos observados por Beleze (2005), que forneceu aos búfalos dieta com $80 \%$ de volumoso e não encontrou diferença para a digestibilidade total da matéria seca para adição de monensina e de controle.

Tabela 3 - Coeficientes de digestibilidade total e parcial de dietas à base de forragem sem ou com adição de monensina e própolis LLOS 3

\begin{tabular}{|c|c|c|c|c|c|c|}
\hline & \multicolumn{4}{|c|}{ Dieta } & \multirow[b]{2}{*}{$\mathrm{P}$} & \multirow[b]{2}{*}{$\mathrm{CV}$} \\
\hline & Controle & Monensina & LLOSC1 & LLOSB3 & & \\
\hline \multicolumn{7}{|l|}{ Digestibilidade total } \\
\hline Matéria orgânica (\%) & $60,0 \mathrm{~b}$ & $60,1 \mathrm{~b}$ & $63,6 a$ & $61,6 a b$ & 0,0031 & 1,41 \\
\hline Proteína bruta (\%) & 55,9 & 57,5 & 59,6 & 57,3 & 0,2302 & 3,84 \\
\hline Extrato etéreo (\%) & $79,8 \mathrm{ab}$ & $80,5 a$ & $80,7 a$ & $75,4 b$ & 0,0332 & 2,60 \\
\hline Carboidratos totais (\%) & $61,5 b$ & $61,5 b$ & $65,1 \mathrm{a}$ & $63,3 a b$ & 0,0081 & 1,70 \\
\hline Carboidratos não-estruturais (\%) & 76,5 & 75,8 & 78,5 & 79,1 & 0,5059 & 4,41 \\
\hline Nutrientes digestíveis totais & $62,3 b$ & $62,5 b$ & $65,8 \mathrm{a}$ & $63,6 a b$ & 0,0117 & 1,64 \\
\hline \multicolumn{7}{|c|}{ Digestibilidade ruminal } \\
\hline Matéria seca ${ }^{1}(\%)$ & $41,6 a$ & $27,4 \mathrm{c}$ & $27,0 \mathrm{c}$ & $31,8 b$ & 0,0001 & 3,52 \\
\hline Matéria seca $^{2}(\%)$ & $70,1 \mathrm{a}$ & $46,1 \mathrm{c}$ & $43,2 c$ & $52,4 b$ & 0,0001 & 3,60 \\
\hline Fibra em detergente neutro ${ }^{2}(\%)$ & $90,7 a$ & $64,1 \mathrm{c}$ & $65,1 \mathrm{c}$ & $80,3 b$ & 0,0001 & 3,99 \\
\hline Fibra em detergente ácido² (\%) & $72,3 a$ & $49,4 b$ & $39,3 c$ & $46,6 b$ & 0,0001 & 3,22 \\
\hline Carboidratos totais ${ }^{2}(\%)$ & 96,8 a & $76,5 \mathrm{bc}$ & $69,9 c$ & $81,9 b$ & 0,0001 & 3,47 \\
\hline Carboidratos não-estruturais¹(\%) & $80,7 a$ & $71,3 b$ & $60,3 c$ & $66,7 \mathrm{bc}$ & 0,0013 & 5,29 \\
\hline Carboidratos não-estruturais²(\%) & $105,8 \mathrm{a}$ & $94,5 \mathrm{ab}$ & $77,0 \mathrm{c}$ & $84,2 \mathrm{bc}$ & 0,0028 & 6,91 \\
\hline \multicolumn{7}{|c|}{ Digestibilidade intestinal } \\
\hline Matéria seca ${ }^{1}$ (\%) & $30,4 \mathrm{c}$ & $44,2 b$ & $48,9 a$ & $42,5 b$ & 0,0001 & 4,57 \\
\hline Matéria seca $^{2}(\%)$ & $29,9 c$ & $53,9 a$ & $56,8 a$ & $47,6 b$ & 0,0001 & 4,05 \\
\hline Matéria orgânica² (\%) & $14,2 \mathrm{c}$ & $34,8 b$ & $41,5 \mathrm{a}$ & $29,2 b$ & 0,0001 & 8,06 \\
\hline Proteína bruta $^{1}(\%)$ & $52,6 b$ & $60,2 \mathrm{a}$ & $63,3 a$ & $60,0 \mathrm{a}$ & 0,0006 & 2,87 \\
\hline Proteína bruta ${ }^{2}(\%)$ & $87,7 \mathrm{c}$ & $112,0 \mathrm{~b}$ & $117,0 \mathrm{a}$ & $112,0 \mathrm{~b}$ & 0,0001 & 0,74 \\
\hline Fibra em detergente neutro ${ }^{1}(\%)$ & 9,9c & $30,1 \mathrm{a}$ & $33,0 a$ & $19,8 b$ & 0,0001 & 10,79 \\
\hline
\end{tabular}

Médias na mesma linha, seguida de letras iguais, não diferem pelo teste Tukey a 5\%.

$1 \%$ do que chega ao compartimento.

$2 \%$ do total digerido.

${ }^{3}$ LLOS: produto em pó à base de extrato de própolis em duas diferentes concentrações de própolis (B e C) e dois teores alcoólicos (1 e 3): LLOSC1 e LLOSB3. 
Não houve efeito das dietas $(\mathrm{P}>0,05)$ para a digestibilidade total da proteína bruta, o que difere das observações de Spears (1990), Rodrigues et al. (2001) e Beleze (2005). De modo geral, espera-se aumento na digestibilidade total da proteína bruta, com a adição de monensina, pelo aumento na quantidade de proteína dietética que chega aos intestinos para ser digerida, como observado por Spears (1990). Ainda, Oliveira et al. (2004), ao avaliarem o efeito da monensina e própolis sobre a produção de amônia e a digestibilidade in vitro da proteína bruta, observaram que a monensina e a própolis reduziram a digestão do tripticale e do farelo de soja pela inibição da produção de amônia. Rodrigues et al. (2001) sugeriram que o efeito da monensina em aumentar a digestibilidade da proteína bruta independe do teor de fibra na dieta, embora a literatura demonstre maior efeito do produto em dietas predominantemente concentradas. Beleze (2005) observou para bovinos e bubalinos maior digestibilidade total da proteína bruta em dietas com $80 \%$ de volumoso com a adição de monensina sódica.

As dietas LLOSC1 e monensina apresentaram maiores coeficientes de digestibilidade total do extrato etéreo $(\mathrm{P}<0,05)$ em relação ao produto LLOSB3, e o controle não diferiu dos demais. Da mesma forma, Lana et al. (2005) observaram que a digestibilidade total do extrato etéreo da dieta contendo própolis, fornecido a cabras, não diferiu do controle. É provável que a redução na digestibilidade total do extrato etéreo observado com o LLOSB3 foi devida às substâncias presentes nesse produto, que podem ter prejudicado a ação das bactérias lipolíticas.

O produto LLOSC1 aumentou $(\mathrm{P}<0,05)$ as digestibilidades totais da fibra em detergente neutro e da fibra em detergente ácido, e, consequentemente, a digestibilidade total dos carboidratos totais em relação à adição de monensina e controle, que não diferiram entre si. O LLOSB3 teve efeito negativo na digestibilidade total da fibra em detergente ácido, que foi inferior às demais dietas $(\mathrm{P}<0,05)$. Todavia, para os carboidratos não estruturais não houve diferença entre dietas.

As diferenças observadas entre os produtos LLOSC1 e LLOSB3 para a digestibilidade total do extrato etéreo e da fibra em detergente ácido podem estar relacionadas não somente a concentração dos flavonoides, mas, também, ao teor alcoólico nesses produtos. Para a mesma concentração de própolis em diferentes extrações alcoólicas, Prado (2005) verificou que no maior teor alcoólico pode estar ocorrendo solubilização de resinas e ceras contaminantes da própolis que estariam influenciando a liberação das substâncias ativas.
Estudos in vitro indicaram que o produto LLOSC1, quando comparado ao LLOSB3, foi tolerado por maior número de cepas, que degradaram todos os diferentes carboidratos testados: celulose, celobiose, arabinose, xilose, frutose, lactose e glicose. Esses dados sugerem que LLOSB3, em relação ao LLOSC1, tem em sua composição determinados compostos que atuam de forma diferente sobre bactérias predominantes em dietas de 100\% de silagem de milho (Prado, 2008). Desta forma, o produto LLOSC1 pode estar selecionando bactérias, cuja maior atividade implique em melhora na digestibilidade total das fibras em detergente neutro e ácido e, consequentemente, na digestibilidade total dos carboidratos totais.

Houve efeito $(\mathrm{P}<0,05)$ das dietas sobre a digestibilidade ruminal da matéria seca e dos nutrientes (Tabela 3). Do total digerido no trato gastrintestinal, o controle propiciou maior digestão ruminal $(\mathrm{P}<0,05)$ para matéria seca, matéria orgânica, proteína bruta, fibra em detergente neutro, fibra em detergente ácido, carboidratos totais e carboidratos não estruturais em relação às demais dietas. Os menores valores de digestibilidade ruminal para as dietas contendo aditivos são um indicativo de alterações na microbiota ruminal, visto que a diferença entre dietas foi somente devido à inclusão dos aditivos alimentares. Atuações diferenciadas dos aditivos sobre as populações de microrganismos também foram observadas, destacando-se o LLOSB3, que influiu menos negativamente sobre a digestão ruminal da matéria seca, matéria orgânica e fração fibrosa da dieta.

A dieta LLOSB3 teve menor efeito sobre a digestibilidade ruminal da matéria seca, matéria orgânica, fibra em detergente neutro, fibra em detergente ácido e carboidratos totais $(\mathrm{P}<0,05)$ em relação a LLOSC1. Isso pode ser atribuído à ação diferenciada dos produtos LLOS sobre as bactérias ruminais, o que está em acordo com os resultados observados por Prado (2005), que observou maior valor para a DIVMS $(\mathrm{P}<0,05)$ de rações com $100 \%$ de feno com a adição de LLOSB3 (49,09\%) em relação a LLOSC1 (45,49\%).

Ainda, em dietas com $100 \%$ de volumoso, Prado (2008) observou que as bactérias tolerantes ao LLOSB3 foram mais especializadas e apresentaram preferências por nichos de fermentação, enquanto as bactérias tolerantes a LLOSC1 apresentaram comportamento mais generalista. Entretanto, a especificidade das bactérias celulolíticas e bactérias fermentadoras de açúcares resistentes a LLOSB3, quando adaptadas ao produto e tendo quantitativamente como principal substrato os carboidratos estruturais, poderia explicar a maior fermentação ocorrida na presença do LLOSB3 em relação a LLOSC1. Esse fato foi confirmado 
pela tendência $(\mathrm{P}<0,07)$ de maior concentração de acetato e butirato $(\mathrm{P}<0,05)$ no líquido ruminal quando o produto LLOSB3 foi adicionado à dieta (Tabela 4).

As dietas monensina e LLOSC1 apresentaram as maiores reduções na digestibilidade ruminal da matéria seca e dos componentes nutritivos. A ação da monensina sobre as bactérias Gram positivas, reduzindo a população de bactérias celulolíticas, foi documentada na literatura (Oehem \& Pickrell, 1999), e, devido à maior parte da matéria seca ter origem na porção fibrosa da dieta, resultou em menor valor da digestibilidade ruminal da matéria seca e da fibra em detergente neutro. Segundo Spears (1990), os efeitos dos ionóforos sobre a digestão da fibra têm mostrado resultados divergentes e a fonte de fibra influencia na resposta ao ionóforo, que, por sua vez, pode afetar a taxa de passagem de sólidos, consequentemente, tendo efeito na digestibilidade da fibra. Neste trabalho, como não foi observada diferença no consumo entre as dietas, o efeito da taxa de passagem não foi à causa da menor digestibilidade ruminal da fibra em detergente neutro.

Ainda não está esclarecido o mecanismo de ação da própolis sobre as bactérias ruminais, entretanto, parecem agir diretamente na duplicação da RNA-polimerase atuante sobre o processo de replicação celular (Takaisi-Kikuni \& Schilcher, 1994). Por sua vez, o modo de ação básico dos ionóforos é a mudança no movimento de íons através de membranas das bactérias Gram-negativas, que altera o gradiente de prótons e, consequentemente, o pH dentro da célula. Na tentativa de manter o pH interno adequado, há gasto de energia adicional, que leva a uma redução no crescimento e na reprodução e, em muitas vezes, até à morte de determinado tipo de bactéria (Russell \& Strobel, 1989). Entretanto, para ambas as dietas, LLOSC1 e monensina, os resultados da digestibilidade ruminal da matéria seca e da fibra em detergente neutro foram semelhantes $(\mathrm{P}>0,05)$.

Houve diferença $(\mathrm{P}<0,05)$ entre as dietas para a digestibilidade ruminal da proteína bruta (\% do que chega ao compartimento). As menores perdas de nitrogênio foram para LLOSC1, seguido por LLOSB3 e monensina, e a maior perda de proteína bruta, na forma de amônia, foi para o controle. Os aditivos LLOSC1, LLOSB3 e monensina podem estar reduzindo a fermentação da proteína ou propiciando sua maior síntese, uma vez que o fluxo de proteína para os intestinos foi aumentado $(\mathrm{P}<0,05)$ em relação ao controle (Tabela 3). A maior razão proteína dietética:microbiana que chega aos intestinos na presença dos ionóforos foi relatada por Spears (1990) e explicou os maiores valores de digestibilidade total da proteína bruta.

Houve diferença para a digestibilidade intestinal da matéria seca (\% do que chega ao compartimento), sendo que o aditivo LLOSC1 apresentou maior coeficiente $(\mathrm{P}<0,05)$, seguido da monensina e LLOSB3, que não diferiram entre si e foram superiores ao controle. Da mesma forma, a digestibilidade intestinal da proteína bruta (\% do que chega ao compartimento) foi inferior $(\mathrm{P}<0,05)$ para o controle em relação à adição dos aditivos (Tabela 3 ).

Com adição de aditivos, observaram-se menores valores na digestibilidade ruminal e alterações no principal local de digestão (rúmen) para a maioria dos componentes nutritivos, que refletiram em aumentos significativos na digestibilidade intestinal. Este fato pareceu mais evidente na dieta LLOSC1, seguida da monensina e do LLOSB3. A a provável mudança de comportamento acarretou aumento nas quantidades de matéria seca e orgânica, proteína bruta, fibras em detergentes neutro e ácido, carboidratos totais e não estruturais que chegam ao intestino para serem digeridos neste compartimento. Outra hipótese é que a ação dos produtos contendo própolis e monensina poderia estar atuando sobre bactérias intestinais, selecionando-as. Segundo Spears (1990), o uso de ionóforos pode afetar a digestão e/ou absorção de nutrientes no rúmen e nos intestinos delgado e grosso. Assim, como observado, o aumento na digestibilidade intestinal da proteína é benéfico, uma vez que aumenta a disponibilidade de aminoácidos para serem absorvidos e utilizados pelas vias metabólicas do organismo animal (Van Soest, 1994).

Os coeficientes de digestibilidade intestinal da fibra em detergente neutro foram superiores para monensina e LLOSC1 em relação ao controle e LLOSB3. Registrou-se diminuição da digestibilidade ruminal da fibra em detergente neutro e aumento da intestinal, principalmente em relação ao controle. Essa alteração, quanto ao principal local de fermentação da fração fibrosa, não teve prejuízo na digestibilidade da fibra, pois a digestibilidade total da fibra em detergente neutro foi superior $(\mathrm{P}<0,05)$ para LLOSC1 e a monensina não diferiu do controle.

Também para a digestibilidade intestinal de carboidratos totais, a dieta LLOSC 1 foi superior $(\mathrm{P}<0,05)$ em relação a LLOSB3 e ao controle, não diferindo da monensina. Para a digestibilidade intestinal da fibra em detergente ácido, a dieta LLOSC1 apresentou valor superior às demais dietas $(\mathrm{P}<0,05)$. Assim, como já citado para outros componentes nutritivos, notou-se uma melhora na eficiência da digestão intestinal com a inclusão de aditivos, em especial a do LLOSC1 e da monensina sódica.

Não houve efeito $(\mathrm{P}>0,05)$ da interação dieta x horário de coleta para valores de $\mathrm{pH}$ e concentrações de nitrogênio amoniacal, porém, houve efeito $(\mathrm{P}<0,05)$ de horário de coleta para ambas variáveis (Figura 1 ) e efeito de dieta para pH ruminal (Tabela 4). 
O valor de $\mathrm{pH}$ ruminal mínimo observado foi de 6,42 , às 4,7 h, após a alimentação. O menor valor de $\mathrm{pH}(\mathrm{P}<0,05)$ foi para LLOSB3 em relação ao controle e à monensina e não diferiu de LLOSC1 (Tabela 4). Ainda, o menor valor observado ficou acima de 6,2, abaixo do qual reduz o crescimento das bactérias celulolíticas (Russell \& Dombrowski,1980). Os altos valores de $\mathrm{pH}$ ruminal foram propiciados pela dieta à base de forragem e pela própria espécie bubalina, que, de modo geral, apresenta valores de $\mathrm{pH}$ ruminal elevados em decorrência da maior secreção salivar e poder tampão da saliva (Sivkova et al., 1997). Beleze (2005) encontrou valor mínimo de pH para bubalinos de 6,6 para dietas à base de forragem.

O valor máximo da produção de nitrogênio amoniacal foi de $21,26 \mathrm{mg} / 100 \mathrm{~mL}$, às 2,18 h, e a produção mínima de $3,15 \mathrm{mg} / 100 \mathrm{~mL}$, às $7,12 \mathrm{~h}$, independente das dietas experimentais (Figura 1). Apesar de o menor valor estar abaixo de 5,0 mg/100 mL de líquido ruminal, recomendado como nível mínimo para que ocorra fermentação (Satter \& Styler, 1974), esse valor volta a níveis aceitáveis, após alimentação, às 8 h. Os bubalinos são mais eficientes no processo de reciclagem de nitrogênio e também na manutenção do balanço positivo de nitrogênio do que bovinos (Kurar \& Mudgal, 1991; Trufchev et al., 1997).

Não houve interação $(\mathrm{P}>0,05)$ de dieta $\times$ horário de coleta para a concentração de ácido acético, ácido propiônico, ácido butírico, AGV totais e razão acetato:propionato, porém, houve efeito $(\mathrm{P}<0,05)$ de horário de coleta (Figura 2). Foi observado efeito cúbico $(\mathrm{P}<0,05)$ para os AGV estudados e para razão acetato:propionato, exceto para acetato, que apresentou comportamento quadrático $(\mathrm{P}<0,05)$.

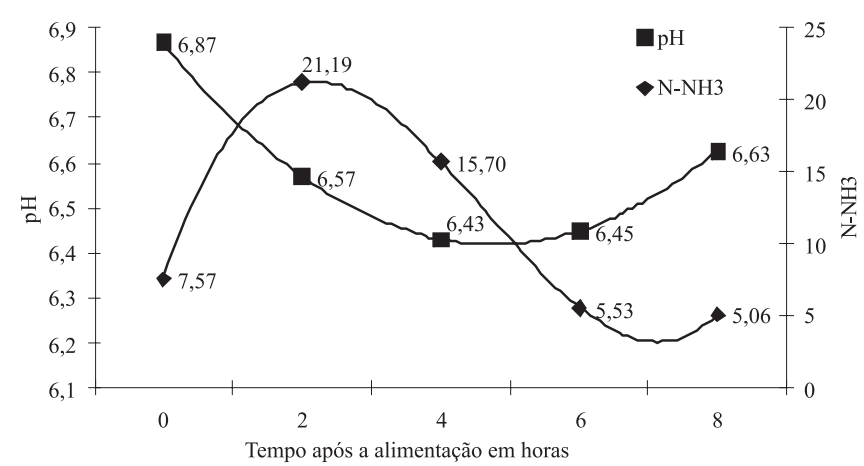

$\mathrm{pH}=0,0197 \mathrm{H}^{2}-0,1874 \mathrm{H}+6,8656 \mathrm{R}^{2}=0,88 ; \mathrm{NH}=0,3 \mathrm{H}^{3}-4,1867 \mathrm{H}^{2}+13,98 \mathrm{H}$ $+7,5729 \mathrm{R}^{2}=0,95$

Figura 1 - pH e concentração de nitrogênio amoniacal $\left(\mathrm{N}-\mathrm{NH}_{3}\right)$ $\mathrm{mg} / 100 \mathrm{~mL}$ após a alimentação para dietas à base de forragem.
Os valores máximos para as concentrações de AGV ocorreram entre 2,6 e 3,0 horas e as concentrações mínimas entre 7,3 e 7,9 horas após a alimentação. Beleze (2005) observou, para bovinos e bubalinos, que as maiores concentrações de AGV ocorreram entre 3,8 e 4,1 horas após a alimentação, provavelmente porque a dieta à base de forragem era composta com $80 \%$ de feno de capim-tifton 85 e neste trabalho $75 \%$ da forragem fornecida foi silagem de milho. A menor razão acetato:propionato foi de 3,44 e ocorreu 3,0 horas após a alimentação. Para a concentração de acetato o valor máximo foi de 52,63 $\mu \mathrm{M} / \mathrm{mL}$ 3,6 horas após a primeira alimentação.

Em valores percentuais, observou-se produção de 66,27\% para acetato, 20,03\% para propionato e 10,08\% para butirato, produções semelhantes às observadas por Beleze (2005) para bovinos e bubalinos, alimentados com dieta que continha 80\% de volumoso e adição de monensina e levedura.

As dietas influenciaram $(\mathrm{P}<0,05)$ a concentração dos ácidos graxos voláteis (Tabela 4). O aditivo LLOSB3 apresentou tendência $(\mathrm{P}<0,07)$ de maior produção de acetato em relação às demais dietas e maior $(\mathrm{P}<0,05)$ concentração de butirato em relação à monensina. Decréscimo no fluxo portal de butirato foi relacionado à adição de monensina sódica em dietas concentradas para novilhos (Spears, 1990). De modo geral, a produção dos AGV para o LLOSB3 foi numericamente superior às demais dietas.

A dieta monensina propiciou a menor razão acetato:propionato $(3,90)$, porém não diferiu $(\mathrm{P}>0,05)$ das demais dietas. LLOSC1 apresentou o segundo menor valor numérico $(4,12)$. Esses resultados parecem ir de encontro com aqueles observados por Lana et al. (2007), que trabalharam com cabras recebendo rações com diferentes níveis de óleo e própolis e encontraram evidências de que a própolis pode diminuir a razão acetato:propionato.

Não houve efeito $(\mathrm{P}>0,05)$ das dietas sobre a taxa de passagem de líquido (11,5\%/hora), provavelmente pelo fato de a concentração de forragem, o teor de fibra em detergente neutro e o consumo serem sido semelhantes entre as dietas (Tabelas 1 e 2). A taxa de passagem de líquido é, em geral, aumentada quando se eleva o nível de consumo e porcentagem de forragem na dieta (Valadares Filho \& Pina, 2006).

Também não houve efeito dos aditivos $(\mathrm{P}>0,05)$ sobre o tempo de retenção ( 8,9 h), taxa de reciclagem ( 2,7 vezes/ dia) e taxa de fluxo (8,0 litros/hora; Tabela 5).

Para dietas com aditivos, houve tendência $(\mathrm{P}<0,08)$ de maior volume ruminal e numericamente maior tempo de retenção de líquido em relação à dieta controle. O menor tempo de retenção de líquido observado para controle pode, em parte, ter influenciado os maiores valores de 

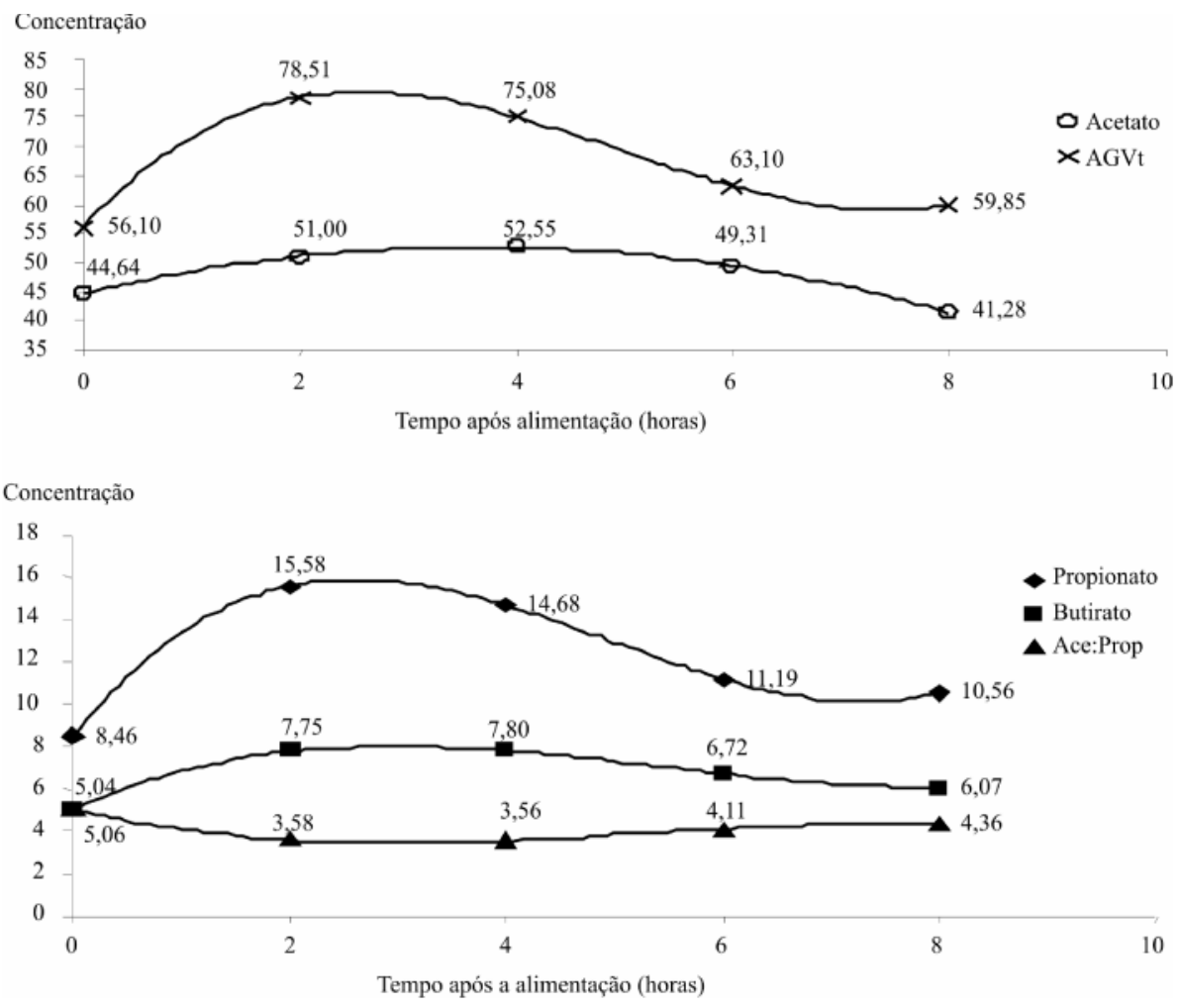

Ace $=-0,5995 \mathrm{H}^{2}+4,3757 \mathrm{H}+44,643 \mathrm{R}^{2}=0,97 ; \mathrm{AGVt}=0,36 \mathrm{H}^{3}-5,3893 \mathrm{H}^{2}+20,543 \mathrm{H}+56,101 \mathrm{R}^{2}=0,97 ;$ Prop $=0,1133 \mathrm{H}^{3}-1,6827 \mathrm{H}^{2}+6,4722 \mathrm{H}+8,4623 \mathrm{R}^{2}=0,97 ;$ But $=0,0323 \mathrm{H}^{3}-0,5279 \mathrm{H}^{2}+2,2836 \mathrm{H}+5,0406 \mathrm{R}=0,99 ;$ Ace:Prop $=-0,01181 \mathrm{H}^{3}+0,2893 \mathrm{H}^{2}-1,2421 \mathrm{H}+5,056 \mathrm{R}^{2}=0,96$

Figura 2 - Concentrações de ácidos graxos voláteis totais, acetato:propionato, butirato (em $\mu \mathrm{M} / \mathrm{mL})$ e razão acetato:propionato após a alimentação de bubalinos com dietas à base de forragem.

Tabela 4 - pH, nitrogênio amoniacal e produção de AGV ruminal de bubalinos alimentados com dieta à base de forragem, com ou sem adição de monensina e própolis LLOS ${ }^{1}$

\begin{tabular}{|c|c|c|c|c|c|c|}
\hline \multirow[b]{2}{*}{ Item } & \multicolumn{4}{|c|}{ Dieta } & \multirow[b]{2}{*}{$\mathrm{P}$} & \multirow[b]{2}{*}{$\mathrm{CV}$} \\
\hline & Controle & Monensina & LLOSC1 & LLOSB 3 & & \\
\hline $\mathrm{pH}$ & $6,62 \mathrm{a}$ & $6,67 \mathrm{a}$ & $6,54 \mathrm{ab}$ & $6,48 b$ & 0,0003 & 2,07 \\
\hline $\mathrm{N}-\mathrm{NH}_{3}(\mathrm{mg} / 100 \mathrm{~mL})$ & 10,83 & 9,94 & 11,29 & 12,15 & 0,4627 & 41,10 \\
\hline AGV totais $(\mu \mathrm{M} / \mathrm{mL})$ & 67,02 & 62,24 & 63,26 & 73,51 & 0,1629 & 27,27 \\
\hline Acetato $(\mu \mathrm{M} / \mathrm{mL})$ & 48,26 & 44,82 & 45,39 & 52,58 & 0,0771 & 23,72 \\
\hline Propionato $(\mu \mathrm{M} / \mathrm{mL})$ & 11,99 & 12,01 & 11,29 & 12,98 & 0,1249 & 23,42 \\
\hline Butirato $(\mu \mathrm{M} / \mathrm{mL})$ & $6,77 \mathrm{ab}$ & $5,42 \mathrm{~b}$ & $6,57 \mathrm{ab}$ & $7,94 a$ & 0,0001 & 24,39 \\
\hline Ace:Prop & 4,33 & 3,90 & 4,12 & 4,21 & 0,2138 & 13,26 \\
\hline
\end{tabular}

Médias na mesma linha, seguida de letras iguais, não diferem estatisticamente pelo teste Tukey a $5 \%$.

${ }^{1}$ LLOS: produto em pó à base de extrato de própolis em duas diferentes concentrações de própolis (B e C) e dois teores alcoólicos (1 e 3): LLOSC1 e LLOSB3.

Tabela 5 - Dinâmica da fase líquida de bubalinos alimentados com dieta à base de forragem, com ou sem adição de monensina e própolis $\operatorname{LLOS}^{1}$

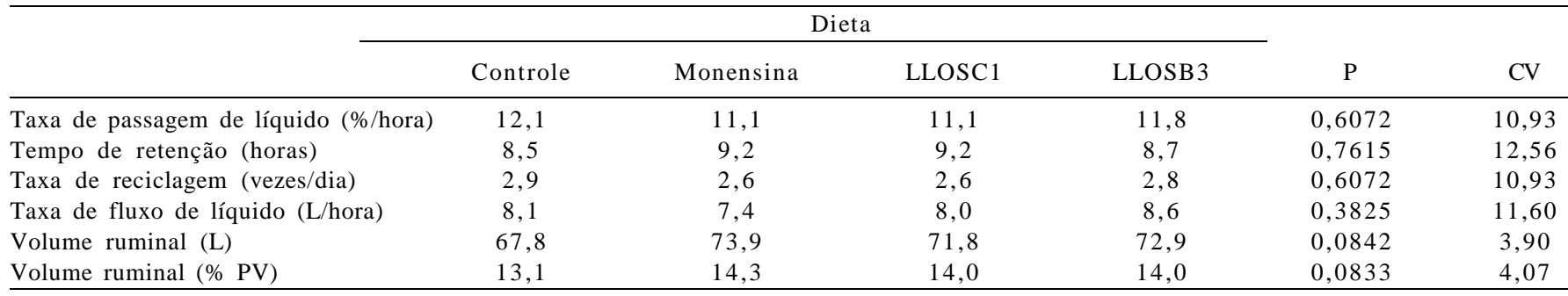

Médias na mesma linha, seguida de letras iguais, não diferem estatisticamente pelo teste Tukey a $5 \%$.

${ }^{1}$ LLOS: produto em pó à base de extrato de própolis em duas diferentes concentrações de própolis (B e C) e dois teores alcoólicos (1 e 3): LLOSC1 e LLOSB3. 
digestão ruminal dos componentes nutritivos para essa dieta. Segundo Van Soest (1994), quando a taxa de diluição no rúmen é elevada, melhoram-se as condições para o crescimento dos microrganismos ruminais até certo ponto, entretanto, se a taxa de diluição for rápida, provavelmente o crescimento microbiano reduzirá.

\section{Conclusões}

O produto à base de própolis LLOSC1 é superior à monensina, pois propicia maior concentração de energia digestível aparente e, quando adicionado em dietas à base de forragem para búfalos, promove aumento nos fluxos de proteína nos intestinos. A monensina sódica e os produtos contendo própolis LLOSC1 e LLOSB3 aumentam a digestibilidade total e intestinal dos componentes nutritivos, porém, com efeitos diversos nas características ruminais. Assim, estudos são necessários para confirmar os efeitos dos ionóforos e das concentrações de própolis em dietas à base de forragem fornecidas a búfalos.

\section{Referências}

AMARAL, F.R.; CARVALHO, L.B.; SILVA, N. et al. Qualidade do leite de búfalas: composição. Revista Brasileira de Reprodução Animal, v.29, n.2, p.1006-1010, 2005.

BERNARDES, O. Bubalinocultura no Brasil: situação e importância econômica. Revista Brasileira de Reprodução Animal, v.31, n.3, p.293-298, 2007.

BELEZE, J.F.R. Digestibilidade e parâmetros ruminais de rações com teores de concentrado e adição de ionóforos ou probiótico para bovinos e bubalinos. 2005. 161f. Tese (Doutorado em Zootecnia) - Universidade Estadual de Maringá, Maringá.

BOCK, B.J.; HARMON D.L.; BRANDT JR., R.T. et al. Fat source and calcium level effects on finishing steer performance, digestion, and metabolism. Journal of Animal Science, v.69, p.2211-2224, 1991.

BROUDISCOU, L.P.; PAPON, Y.; BROUDISCOU, A.F. Effects of dry plant extracts on fermentation and methanogenesis in continuous culture of rumen microbes. Animal Feed Science and Technology, v.87, n.3-4, p.263-277, 2000.

COELHO DA SILVA, J.F.; LEÃO, M.I. Fundamentos de nutrição dos ruminantes. Piracicaba: Editora Livroceres, 1979. 380p.

COLUCCI, P.E. Comparative digestion and digesta kinetics in sheep and cattle. 1984. 221f. Thesis (Ph.D. in Animal Science) - University of Guelph, Guelph.

COLUCCI, P.E.; MACLEOD, G.K.; GROVUM, W.L. et al. Digesta kinetics in sheep and cattle fed diets with different forage to concentrate ratios at high and low intakes. Journal of Dairy Science, v.73, n.8, p.2143-2156, 1990.

FENNER, H. Methods for determining total volatile base in rumen fluid by steam distillation. Journal of Dairy Science, v.48, n.3, p.249-251, 1965.

FRANCO, S.L.; BUENO, J.H.F. Otimização de processo extrativo de própolis. Infarma, v.11, n.11/12, p.48-51, 1999.

ÍTAVO, C.C.B.F.; MORAIS, M. G.; COSTA, C. et al. Características de carcaça, componentes corporais e rendimento de cortes de cordeiros confinados recebendo dieta com própolis ou monensina sódica. Revista Brasileira de Zootecnia, v.38, n.5, p.898-905, 2009.
JOHNSON K.A.; JOHNSON, D.E. Methane emissions from cattle. Journal of Animal Science, v.75, p.2483-2492, 1995.

KIMURA, F.T.; MILLER, V.L. Chromic oxide measurement. Improved determination of chromic oxide in cow feed and feces. Journal of Agricultural and Food Chemistry, v.5, p.216, 1957.

KURAR, C.K.; MUDGAL, V.D. Maintenance requirements for protein in buffaloes. Indian Journal Animal Science, v.51, n.6, p.817-823, 1981.

LANA, R.P.; RUSSELL, J.B. Efeitos da monensina sobre a fermentação e sensibilidade de bactérias ruminais de ovinos sob dietas ricas em volumoso ou concentrado. Revista Brasileira de Zootecnia, v.30, n.1, p.254-260, 2001.

LANA, R.P.; CAMARDELLI, M.M.L.; QUEIROZ, A.C. et al. Óleo de soja e própolis na alimentação de cabras leiteiras. Revista Brasileira de Zootecnia, v.34, n.2, p.650-658, 2005.

LANA, R.P.; CAMARDELLI, M.M.L.; RODRIGUES, M.T. et al. Óleo se soja e própolis na alimentação de cabras leiteiras: consumo de matéria seca e de nutrientes e parâmetros de fermentação ruminal. Revista Brasileira de Zootecnia, v.36, n.1, p.191-197, 2007.

LEÃO, M.I.; VALADARES FILHO, S.C.; RENNÓ, L.N. et al. Consumos e digestibilidades totais e parciais de carboidratos totais, fibra em detergente neutro e carboidratos não-fibrosos em novilhos submetidos a três níveis de ingestão e duas metodologias de coleta de digestas abomasal e omasal. Revista Brasileira de Zootecnia v.34, n.2, p.670-678, 2005

LIRA, G.M.; MANCINI FILHO, J.; TORRES, R.P. et al. Composição centesimal, valor calórico, teor de colesterol e perfil de ácidos graxos da carne de búfalo (Bubalis bubalis) da cidade de São Luiz do Quitunde - AL. Revista Instituto Adolfo Lutz, v.64, p.31-38, 2005.

MAENG, W.J.; BALDWIN, R.L. Dynamics of fermentation of purified diet and microbioal growth in the rumen. Journal of Dairy Science, v.59, n.4, p.636-642, 1976.

OEHEM, F.W.; PICKRELL, J. An analysis of the chronic oaral toxicity of polyether ionophore antibiotics in animals. Veterinary and Human Toxicology, v.41, p.251-257, 1999

OLIVEIRA, J.S.; LANA, R.P.; BORGES, A.C. et al. Efeito da Monensina e Extrato de própolis sobre a produção de amônia e degradabilidade in vitro da proteína bruta de diferentes fontes de nitrogênio. Revista Brasileira de Zootecnia, v.33, n.2, p.504-510, 2004.

OLIVEIRA, M.V.M.; LANA, R.P.; JHAM, G.N. et al. Influência da monensina no consumo e na fermentação ruminal em bovinos recebendo dietas com teores baixo e alto de proteína. Revista Brasileira de Zootecnia, v.34, n.5, p.1763-1774, 2005.

PRADO, O.P.P. Produto à base de própolis na nutrição de ruminantes (LLOS). 2005. 78f. Dissertação (Mestrado em Produção Animal) - Universidade Estadual de Maringá, Maringá.

PRADO, O.P.P. Própolis e monensina sódica em dietas volumosas sobre a digestibilidade e características ruminais de bovídeos. 2008. 92f. Tese (Doutorado em Produção Animal) - Universidade Estadual de Maringá, Maringá.

RODRIGUES, P.H.M.; MATTOS, W.R.S.; MELOTTI, L. et al. Monensina e digestibilidade aparente em ovinos alimentados com proporções de volumoso/concentrado. Scientia Agrícola, v.58, n.3, p.449-455, 2001.

RUSSELL, J.B.; STROBEL, H.J. Effect of ionophores on ruminal fermentation. Applied and Environmental Microbiology, v.55, p.1-6, 1989.

RUSSELL, J.B.; DOMBROWSKI, D.B. Effect of $\mathrm{pH}$ on the efficiency of growth by culteres of rumen bacteria in continous culture Applied and Environmental Microbiology, v.39, 604p. 1980.

SATTER, L.D.; SLYTER, L.L. Effect of ammonia concentration on rumen microbial protein production in vitro. Britanic of Journal Nutrition, v.32, n.2, p.199-205, 1974. 
SILVA, D.J.; QUEIROZ, A.C. Análises de alimentos. 3.ed. Viçosa, MG: UFV, Imprensa Universitária, 2002. 235p.

SIVKOVA, K.; TRUFCHEV, H.; VARLIAKOV, I. Comparative studies on fermentation processes in the rumen and blood content of calves and buffalo calves I. Effect on diet, containing alfafa haylage. In: WORLD BUFFALO CONGRESS, 5., 1997, Caserta. Proceedings... Caserta: 1997. p.312-316.

SNIFFEN, C.J.; O’CONNOR, J.D.; VAN SOEST, P.J. et al. A net carbohydrate and protein system for evaluating cattle diets: II. Carbohydrate and protein availability. Journal of Animal Science, v.70, n.12, p.3562-3577, 1992.

SPEARS, J.W. Ionophores and nutrient digestion and absorption in ruminants. Journal of Nutrition, v.120, n.6, p.632-638, 1990.

STATISTICAL ANALYSIS SYSTEM - SAS. Procedures guides. Version 6. Cary: SAS Institute, 2004. 176p.

STELZER, F.S.; LANA, R.P.; CAMPOS, J.M. et al. Desempenho de vacas leiteiras recebendo concentrado em diferentes níveis, associado ou não à própolis. Revista Brasileira de Zootecnia, v.38, n.7, p.1381-1389, 2009.

STRADIOTTI JR., D.; QUEIROZ, A.C.; LANA, R.P. et al. Ação da própolis sobre a desaminação de aminoácidos e a fermentação ruminal. Revista Brasileira de Zootecnia, v.33, n.4, p.1086-1092, 2004.
TAKAISI-KIKUNI, N.B.; SCHILCHER, H. Electron microscopic and microcalorimetric investigations of the possible mechanism of the antibacterial action of a defined propolis provenance. Planta Medicine, v.60, n.2, p.222-227, 1994.

TRUFCHEV, H.; SIVKOVA, K.; ZANKOVA, M. Comparative studies on fermentation processes in the rumen and blood content of calves and buffalo calves. II. Effect on diet, containing maize silage. In: WORLD BUFFALO CONGRESS, 5., 1997, Caserta. Proceedings... Caserta: 1997. p.312-316.

UDEN, P.; COLUCCI, P.E.; VAN SOEST, P.J. Investigation of chromium, cerium and cobalt as markers in digesta. Rate of passage studies. Journal of the Science of Food and Agriculture, v.31, n.7, p.625-632, 1980.

VALADARES FILHO S.C.; PINA, D.S. Fermentação ruminal. In: BERCHELli, T.T.; PIRES, A.V.; OLIVEIRA, S.G. (Orgs). Nutrição de ruminantes. Jaboticabal: Funep, 2006. v.1, p.151-182.

VAN SOEST, P.J.; ROBERTSON, J.B.; LEWIS, B.A. Methods for dietary fiber, neutral detergent fiber, and nonstarch polyssacharides in relation to animal nutrition. Journal of Dairy Science, v.74, n.10, p.3583-3597, 1991.

VAN SOEST, P.J. Nutritional ecology of the ruminant. 2.ed. Ithaca: Cornell University Press, 1994. 476p. 